\title{
NARRATIVAS DE CRISE: CRISE DE IDENTIDADE, CRISE DE SENTIDO?!
}

\author{
Roseli Araújo Barros Costa ${ }^{1}$ \\ Tadeu Oliver Gonçalves ${ }^{2}$
}

\section{RESUMO}

Este artigo é relativo a um recorte de uma pesquisa mais ampla sobre a compreensão do desenvolvimento profissional de professores de Matemática, em especial, dos resultados da análise de uma das categorias selecionadas, as professoras e as narrativas de crise. Tal análise apoiou-se teoricamente em Larrosa (2002). Para a realização da investigação, adotamos a pesquisa qualitativa, com enfoque narrativo, com base em entrevistas semiestruturadas sobre a história de vida de uma professora que ensina matemática na Educação Básica. Alicerçada em um conceito de desenvolvimento profissional tomado numa perspectiva contínua, idealizado num contexto mais amplo do trabalho docente, permeando crises e conflitos, a análise evidencia que os relatos de crise da professora estão relacionados a fatores como: baixos salários, conflitos em sua atual instituição de trabalho, escasso prestígio social e insegurança. Seus relatos revelam que a formação inicial em nada contribuiu para que enfrentasse as "novas" mudanças na educação. Mostra que a sua falta de entusiasmo está associada ao esvaziamento do sentido útil de sua formação, que decorre da sobrevalorização do seu valor de troca. No entanto, uma narrativa de crise pode edificar o presente como um momento crítico no duplo sentido da palavra, como um momento decisivo e, ao mesmo tempo, como um momento no qual o sujeito recupera de forma crítica sua própria história, apropria-se criticamente dela, para saber onde se encontra e para decidir seu próprio movimento (LARRROSA, 2002). O indivíduo, ao restaurar de modo crítico sua história, pode repensar o passado, pensar o presente e (re) construir o seu próprio futuro. A professora, em suas narrativas de crise, mostra que, ao recuperar criticamente sua história, colocando para fora de si toda sua "revolta", abre uma "porta" que possivelmente mostrará um novo caminho a ser tomado. Assim, a professora mostra indícios de que busca novos desafios para o seu desenvolvimento profissional.

Palavras Chaves: Investigação Narrativa; Narrativas de crise; Desenvolvimento profissional.

\section{INTRODUÇÃO}

A questão discutida neste texto surgiu a partir de uma pesquisa cujo principal objetivo foi compreender o desenvolvimento profissional de professores de Matemática em Araguaína, Tocantins. Partindo da percepção de que a nossa inquietação acerca do assunto não era recente e de que fazia parte da trajetória profissional de um dos autores, centralizamos nosso foco de investigação em torno do seguinte questionamento: Como é que cada um se tornou o professor que é hoje? E por quê?

Obtivemos respostas ao nosso questionamento a partir da investigação das vivências de quatro professoras de Matemática da Rede Pública Estadual em Araguaína, Tocantins, que descreveram como ocorreu o seu desenvolvimento profissional, ao se tornarem as professoras que eram quando as entrevistamos. Considerando-as em sua integralidade, num primeiro momento, construímos uma descrição detalhada da história de vida de cada uma delas, a partir de suas próprias vozes. E, num segundo momento, na análise de seus depoimentos, buscamos o desenvolvimento profissional a partir de seis categorias, que emergiram da leitura e releitura de suas falas: (1) vivência das professoras como alunas do Ensino Fundamental e Médio (EFM); (2) vivência das professoras como alunas em cursos de formação de professores; (3) vivência das professoras como docentes do EFM; (4) vivência das professoras como docentes em cursos de formação de professores; (5) as professoras refletindo sobre a

${ }^{1}$ Mestre em Educação em Ciências e Matemáticas: Educação Matemática pela Universidade Federal do Pará - PPGECM/ IEMCI/UFPA. ${ }^{2}$ Doutor em Educação pela UNICAMP, Professor do Programa de Pós-Graduação em Educação em Ciências e Matemáticas - PPGECM/ IEMCI/UFPA. 
prática; (6) as professoras e as narrativas de crise.

Alicerçado em um conceito de desenvolvimento profissional tomado numa perspectiva contínua, idealizado num contexto mais amplo do trabalho docente, permeando crises, conflitos e contradições (IMBERNÓN, 1994), o estudo evidenciou que manifestações de desenvolvimento profissional, tendo como base as vivências, ocorreram indistintamente entre as professoras. Isto é, o desenvolvimento profissional é reconhecido por meio dos saberes que emergem de suas experiências, o que Melo (2003) denomina de "saberes da vivência".

Para compreendermos melhor o desenvolvimento profissional das professoras, adotamos como método a pesquisa qualitativa, com enfoque narrativo (CONNELLY e CLANDININ, 1995), utilizando depoimentos das professoras obtidos por meio de entrevistas semi-estruturadas. A escolha pela investigação narrativa ocorreu por acreditarmos que uma metodologia deve criar uma atmosfera de reflexão por parte dos professores e do próprio investigador sobre a sua prática, estabelecendo uma ponte para a comunicação entre as suas ideias e as do investigador. Tal abordagem de pesquisa qualitativa pode promover a aproximação de conceitos, opiniões, experiências e prática dos sujeitos, a partir de suas próprias percepções.

As entrevistas aconteceram, entre fevereiro e julho de 2004, em momentos individuais e optamos por chamá-las de "depoimentos dialogados" (GARNICA, 2003), que foram gravados em áudio e, posteriormente, transcritos. Considerando que se tratava da busca de uma realidade nãodocumentada, as entrevistas tiveram um roteiro planejado, na modalidade semi-estruturada, de forma a dar às professoras a possibilidade de seguirem seus próprios rumos narrativos. $\mathrm{O}$ enfoque semi-estruturado e dialogado permitiu que o entrevistado relatasse a sua história, com critérios de significado pessoal.

Entre as idas e vindas ao material empírico da pesquisa, deparamo-nos com situações em que tivemos de interromper a análise das entrevistas e buscar auxílio na literatura, para interpretar as falas expressas nos depoimentos. Um desses momentos foi ante ao seguinte relato: "[...] eu já amei a educação, já me dediquei demais da conta, mas hoje eu faço de conta [...] estou numa fase horrível da minha vida" (Esperança, entrevistajulho/2004).
Portanto, este texto trata, em especial, dos resultados da análise de uma das categorias selecionadas em nossa pesquisa, intitulada as professoras e as narrativas de crise que, embora não sendo comum a todos os sujeitos, também estavam implícitas em alguns relatos. Foi essa categoria que recortamos da pesquisa completa para a construção deste artigo. Para tanto, inicialmente, descrevemos a trajetória pessoal e profissional da professora, a partir de "fragmentos" de sua própria voz. Em seguida, apresentamos a análise da categoria acima anunciada.

\section{A HISTÓRIA DE VIDA DE ESPERANÇA}

A mão tocava o teclado do computador e pensava: Como anunciar essa trajetória de vida? Por onde começar? Desde o dia em que entrevistamos Esperança, temíamos por aquele momento, uma vez que escrever sobre ela parecia-nos um tanto quanto "complexo" e ao mesmo tempo "desafiador". Surgiu então outro questionamento: Como narrar essa história? Buscávamos palavras, mas elas pareciam insuficientes. A vida de Esperança não tinha sido nada fácil e exigia mais do que simples palavras para narrar sua trajetória. Tivemos que voltar ao início de tudo, para tentarmos montar este "quebra-cabeça", combinando cada pedacinho para nos aventurarmos a compreender cada palavra. Todavia, nem sempre foi assim...

Esperança nasceu em Conselheiro Pena, em Minas Gerais, em uma fazenda conhecida como João Carreiro. Sua trajetória estudantil foi marcada por dificuldades, lutas e desafios de estudar em uma escola na zona rural: " [...] a gente ia a cavalo [...] lembro que, na época, a gente levava um litro de leite para lanchar, porque não tinha lanche na escola". Ao recordar os primeiros anos escolares, falou com carinho da professora Alice: "[...] a pessoa que mais eu queria rever era a minha professora da $4^{a}$ série [...] essa professora admiro até hoje”. Essa professora foi quem despertou em Esperança o desejo de ensinar: "[...] eu a achava muito bonita e pensava: um dia eu vou ser professora".

Em 1972, a família veio para o Estado do Tocantins (na época, Estado de Goiás) e foram residir em uma fazenda a $22 \mathrm{~km}$ da cidade de Xambioá, conhecida como Fazenda da Mata. As dificuldades de acesso à escola resultaram na interrupção de seus estudos: “[...] eu sempre fui 'inspirada' para estudar, mas meu pai dizia que era muito difícil deixar as filhas dele saírem [...] não fui estudar, meus irmãos 
foram e eu fiquei". Esperança, na época com 12 anos, ficou trabalhando na fazenda. Entretanto, o desejo de ser professora parece que "falou mais alto" e começou a alfabetizar os filhos dos vizinhos da fazenda, segundo relata:

\begin{abstract}
[...] Eu trabalhava na roça, cortava a roça de facão, enxada e machado [...] comecei a "puxar um horário" para ensinar os filhos dos vizinhos, era de cinco às sete horas, porque não podia ficar até mais tarde, tinha que levantar no outro dia às quatro horas para fazer a comida, levar para a roça e continuar trabalhando [...] eram quinze alunos, eu os alfabetizava.
\end{abstract}

O prefeito da cidade de Xambioá, ao visitar a fazenda, ficou conhecendo seu trabalho e achou interessante uma menina alfabetizando e construiu uma pequena escola. Assim, nasceu a Escola M.A. Esperança. Em seu relato, fala sobre o ambiente improvisado em que desenvolvia suas atividades:

\begin{abstract}
[...] Antes de construir a escola tudo era improvisado, eles colocavam aquelas forquilhas, cortavam pés de açai e faziam os banquinhos [...] faziam pranchas de raiz de árvore e mesinhas [...] eu ensinava assim: seis aqui, três ali... Eram dois bancos com doze lugares. O quadro era a raiz de uma árvore chamada gameleira, que dá uma raiz bem grande, bem larga e a gente escrevia com carvão. Aíjogava água, secava com um pano, esperava o sol secar o resto e escrevia novamente.
\end{abstract}

Ela continuou trabalhando na roça e ensinando as crianças, mas acabou ficando muito doente: "[...] eu fui para a roça, capinei o dia todo, deu uma supuração de apendicite. Fui para o médico, quase morro". Ao afastar-se da escola, surgiu a oportunidade de voltar a estudar, quando uma professora que Esperança chama de "Dona Lu”, convidou-a para trabalhar em sua casa na cidade de Xambioá como doméstica.

Assim, estudou a $5^{\mathrm{a}}, 6^{\mathrm{a}}, 7^{\mathrm{a}}$ e $8^{\mathrm{a}}$ séries do EF em Xambioá. Quando estava na $6^{\mathrm{a}}$ série, Dona $\mathrm{Lu}$ ofereceu-lhe um emprego, com duas opções: poderia lecionar na Rede Pública Estadual ou trabalhar em um escritório de Contabilidade. Esperança manifestou o desejo de trabalhar no escritório, mas Dona Lu, mesmo mostrando duas opções de escolha, dizia que trabalhar na escola seria melhor: "[...] fui ser secretária de uma escola. Só que toda a vida eu tinha vontade de ensinar, não era de trabalhar assim". Porém, parece que seu destino era mesmo ser professora: "[...] Deus é tão bom e justo que meu contrato de trabalho sai como professora". Mesmo assim, trabalhou por dois anos na secretaria da escola. Como o seu contrato de trabalho não era administrativo, as pessoas começaram a incentivá-la a lecionar. Naquele momento, sentiu que seu desejo poderia se concretizar, todavia, vivia cercada de dúvidas e de receios:

[...] Eu tinha vontade de ter uma sala, com alunos só de uma série [...] a escola na fazenda, era muito variada, era $1^{a}, 2^{a}, 3^{a}$ e $4^{a}$ séries [classe multiserriada]. A $4^{a}$ série, meu Deus! Eu tinha muito medo, porque eu não sabia, eu tinha feito somente a $5^{a}$ série, como eu ia ensinar?

Em 1977, ensinou pela primeira vez em uma escola pública: "[...] fui trabalhar com alfabetização, daquele jeito como fui alfabetizada: não sabe o A, fica de castigo e apanha para aprender, bem tradicional". Apesar de descrever sua prática docente dessa forma, considerou que: "[...] naquela época fui uma boa alfabetizadora".

Ao terminar a $8^{\mathrm{a}}$ série, casou-se e foi morar em um povoado conhecido como Mosquito, localizado ao norte do Estado do Tocantins, hoje, Palmeiras do Tocantins: "[...] fiquei lá 14 anos [...] trabalhei dois anos na secretaria porque tinha experiência, contra a minha vontade e os outros anos trabalhei na sala de aula". Nessa época, conseguiu dar continuidade aos seus estudos, fazendo um curso de nível médio, Magistério, em um Centro de Formação de Professores, localizado na cidade de Tocantinópolis, região do Bico do Papagaio. Apesar de já ter uma filha de onze meses, foi viver nessa cidade: "[...] lá a gente era interna, de $15 \mathrm{em} 15$ dias você tinha o direito de ir ver a família”. Assim, ficou como interna no Centro de Formação de 1983 e 1984. Em 1985, retornou à cidade de Palmeiras para concluir o estágio em uma escola.

Ao regressar para a cidade, começou a lecionar Matemática na Rede Pública Estadual e assumiu também a direção de um colégio, da Rede Pública Municipal, sendo uma das fundadoras. No entanto, em 1993, devido a problemas familiares, passou a residir em Araguaína, onde começou a trabalhar na Escola AL. Nessa escola, ficou exercendo o cargo de professora de Matemática, de 1993 a 1997. 
Em 1998, fez seleção para o vestibular em Licenciatura em Matemática, oferecido pela Universidade do Tocantins (UNITINS), no Campus de Miracema: "[...] eu ia daqui pra Miracema, porque estudávamos mês sim, mês não". Consequentemente, acabou sendo transferida da sala de aula para a secretaria da escola: "[...] eu só fui para a secretaria da escola, porque passei no vestibular [...] aqueles que julgavam a Escola $A L$ prioritária no Tocantins e modelo em Araguaína não deixaram eu ficar na sala de aula”.

Em 2000, devido às dificuldades de estudar em outra cidade, optou por morar na cidade de Miracema. Nesse contexto, começou a trabalhar na escola EB como professora de Matemática. O curso de Licenciatura em Matemática era ofertado em regime especial, os alunos tinham entre 30 e 55 anos de idade e a maioria apenas com formação em nível médio, curso de Magistério. Com relação ao curso, esclarece em seu depoimento que: "[...] foi uma coisa muito puxada [...] nos deparamos com a Matemática e não teve muita 'cobertura' dos professores [...] nos preparamos para uma coisa e era completamente diferente". Apesar das dificuldades enfrentadas, concluiu o curso de graduação Licenciatura em Matemática, em 2003.

Em 2004, conseguiu ser transferida para a cidade de Araguaína e passou a trabalhar na Escola M, da Rede Pública. Atualmente, no período de férias escolares, leciona nos cursos de Pedagogia, Normal Superior e Licenciatura em Matemática, na cidade de Redenção, no Estado do Pará. Os cursos são ofertados em regime especial, promovido pela Universidade Estadual do Pará (UEPA) e leciona disciplinas como: Matemática e Metodologia do Ensino de Matemática. Também em Redenção, aos finais de semana, leciona no curso Pró-formação: "[...] eu leciono Didática da Matemática”.

Esperança cresceu ensinando para outras crianças o que aprendeu. Apesar de sua trajetória de vida ser dedicada à educação, percebemos em seus relatos uma grande decepção consigo própria. Assim, tratamos, a partir de agora, da complexidade de algumas falas de Esperança, que chamamos de "narrativas de crise".

\section{NARRATIVAS DE CRISE}

Larrosa (2002), em Nietzche \& a Educação, fala sobre a "Libertação da liberdade para além do sujeito". Em suas primeiras palavras, assim dirige-se ao leitor:

[...] Vou lhes contar um conto. Um conto que, como todos os contos, relata uma travessia, ou uma passagem e ao mesmo tempo uma metamorfose. Um conto, ademais, de final aberto como nossa perplexidade. Um conto cujo protagonista é o sujeito, porém o sujeito entendido a partir do modo em que se constitui na Modernidade, a partir do modo da liberdade. [...] um conto que joga algo do que somos, um certo modo de subjetividade, uma certa maneira de nomear o sentido ou não-sentido daquilo que nos passa, uma certa forma de vida, uma certa ética e uma certa estética da existência (LARROSA, 2002, p. 81).

Ao abordar o tema, Larrosa (2002) subdivide-o em vários momentos. Destacamos alguns deles: no primeiro, o autor se refere à liberdade como maioridade, como emancipação, como autonomia, como a propriedade de um sujeito que se libertou de todo tipo de submissão e passou a ser dono de si mesmo e de sua história. Num segundo momento, que praticamente inverte o primeiro, fabula a liberdade como infância, como criação, como início, como acontecimento. A liberdade, já não está ao lado de um sujeito que se constitui como tal na autoconsciência e na autodeterminação, mas, precisamente, pela transformação poética e estética da existência.

Larrosa (2002), a partir do primeiro momento (texto), conta uma história que, segundo ele, poderia se intitular como a "Libertação da liberdade", utilizando como ponto de partida um texto de Kant. A partir desse texto, chega a uma liberdade subjetiva, que vai perdendo o impulso, entra em crise, perde a confiança em si mesma, começa a não se suportar e, enfim, salta para fora de si mesma, libertando-se e buscando uma nova direção.

Nesse momento, percebemos que havíamos encontrado o que procurávamos e com esse novo olhar, compreendemos que Esperança, ao perder a sua liberdade, entrou em crise e perdeu a confiança em si. Por não suportar o que tanto a inquietava, acabou colocando para fora de si mesma toda a sua "revolta", abrindo-se em direção à outra coisa, ou seja, algo novo.

Nesse sentido, em todas as variantes dessa "fábula" que combina em uma mesma rede as figuras do Homem, da Liberdade, da Razão e da 
[...] que se levanta seguro de si mesmo e começava a andar racionalmente e com pé firme no relato Kantiano, aparece agora envelhecido, cansado, quase desfalecido, a ponto de perder a fé em si mesmo, e tentando desesperadamente extrair alguma esperança, alguma força vital, algum sustento interior rescaldos ainda fumegantes de sua própria juventude (LARROSA, 2002, p.88).

Em Praga, em 1935, Husserl (apud LARRROSA, 2002) proferiu uma conferência sobre $A$ crise das Ciências como expressão da crise vital da humanidade européia. Nessa, apresentou a narrativa de crise, descrevendo uma estrutura muito convencional que pode ser analisada sob quatro momentos:

[...] (1) Era uma vez, faz muito tempo, em algum momento da história do que somos, em que algo, talvez a liberdade, se dava por suposta ou se anunciava esplendorosa no horizonte [...] houve um tempo em que éramos jovens, em que estávamos cheios de ideais e de confiança em nós mesmos, em que sabíamos claramente o que éramos e o que queríamos; (2) agora não obstante todos esses ideais estão desmoronando ao nosso redor e nos sentimos velhos e cansados; (3) mas não podemos perder a confiança em nós mesmos porque, se a perdermos, não somente teremos fracasso, senão que nossa própria história não terá sentido; (4) necessitamos, portanto, renovar e revitalizar nossa fé e nossa esperança de juventude, mesmo que seja de outra forma, com outras bases; outra, não obstante a mesma, se queremos que nossa história tenha futuro, que o que fomos e quase estamos deixando de ser se projete até o futuro (HUSSERL, apud LARROSA, 2002, p. 89).

Esse "novo olhar" projetado à análise das falas de Esperança foi reforçado, quando encontramos na literatura que:

[...] Uma narrativa de crise constrói o presente como um momento crítico no duplo sentido da palavra, como um momento decisivo e ao mesmo tempo como um momento de crítica, como um momento no qual o sujeito recupera criticamente sua própria história, apropria-se criticamente de sua própria história, para saber onde se encontra e para decidir seu próprio movimento (LARROSA, 2002, p. 89).
Haja vista que se trata de uma narrativa de crise, para Larrosa (2002), ouvindo estas falas, muitas delas exaltando o caótico, de forma genérica, chegase à ideia de problemas. Ao mesmo tempo, a fala sobre o presente é afetada pela premissa de que se vivem sucessivas crises. A concepção de crise aqui tem um sentido negativo, fornece a ilusão de caos, de perda do significado, de fim. Algo que é expresso no seguinte depoimento:

[...] Quando você chega a uma época como eu estou, com 28 anos de serviço, com 44 anos de idade, uma pessoa que se desgastou demais, teve o tempo dedicado à educação e hoje sofre, porque viveu isso uma vida inteira [...] fui professora que me dediquei de corpo e alma, que amei minha profissão. Hoje, não detesto minha profissão [...], mas tenho medo. Sou frustrada, decepcionada demais com a educação e como sou decepcionada! (Esperança, entrevista Jul/2004).

Uma narrativa de crise apresenta esse duplo sentido da palavra e, quiçá, por isso:

[...] Os relatos de crise tenham esse tom apocalíptico, esse tom de fim de mundo, esse tom de grandes apostas e grandes decisões, esse tom de morte e renascimento, esse tom de estado crítico, de enfermidade quase mortal e remédios desesperados, esse tom heróico, esse tom, definitivamente, de perdição ou salvação (LARROSA, 2002, p. 89-90).

Os relatos de crise indicam que se trata de uma crise de fé, de ânimo, de autoconfiança, de vitalidade, de esperança, uma crise "moral", quase no sentido desportivo da expressão. A professora se sente desmoralizada, desanimada, desiludida, frustrada, decepcionada, como diz. Por quê? Larrosa (2002, p. 95) ajuda-nos a responder essa pergunta, quando diz: "[...] porque lhe falta uma idéia de si própria ou uma fábula de si mesma na qual possa reconhecer-se e sustentar-se. Porque lhe abandonou o ânimo, o espírito, a ideia interior que lhe dava vida".

Como se trata de uma narrativa de crise, selecionamos um parágrafo que expressa bem esse tom de perda, de nostalgia, em suma, que contrasta com o tom juvenil de outrora. O parágrafo diz:

[...] Na época que eu tinha a $4^{a}$ série eu era a professora Esperança. Hoje, eu sou uma 
professorinha de Matemática, uma professorinha que desmaia dentro da sala de aula [...] uma pessoa que tem depressão [...] que não ganha bem [...] que tem 45 alunos dentro de uma sala, que grita, te humilha, te xinga e você não tem o direito de dizer nada [...] sou uma professora e não fui educada para isso [...] meus pais, quando me educaram, não foi para que não respondesse a ninguém [...] que não fosse uma pessoa agressiva, intolerante, mas que dentro de seus direitos, você fosse alguém. Porque hoje eu não sou ninguém (Esperança, entrevistaJul/2004).

Essa narrativa de caos talvez ocorra porque o homem perdeu o sentido de si próprio, porque não encontra nenhuma ideia de liberdade para dar sentido a sua própria história. Ele já não se tem a si mesmo como sujeito, não tem nenhuma ideia de si mesmo para realizar e encontra-se abandonado à ingênua faticidade de sua existência, comprometido com uma situação não escolhida. Husserl (apud LARROSA, 2002,p. 96) afirma que:

[...] Cai também a fé em uma razão na qual o homem possa encontrar seu sentido, a fé no sentido da história, no sentido da Humanidade, em sua liberdade, ou o que é igual, na capacidade e possibilidade do homem de conferir a sua existência humana, individual e geral, um sentido racional. A perda, por parte do homem, desta fé significa nada mais e nada menos que a perda da fé em si mesmo, no ser verdadeiro que lhe é próprio, um ser que não possui deste sempre, que não possui deste a mera evidência do "eu sou" mas que só tem e só pode ter como próprio lutando sempre por sua verdade, lutando por fazer-se a si mesmo verdadeiro, e no marco desta luta

Esperança talvez seja alguém que não consiga dar sentido à sua própria história. Sua história evidencia um confronto entre o sonho e a realidade de uma profissão. Mostra os sonhos de alguém que quando criança "brincava" de ser professora, brincadeira essa que se transformou em profissão. Todavia, com o tempo, confrontando-se com a realidade, essa jornada tornou-se árdua e complexa, Esperança perde a esperança do sonho, do poder da transformação, vê-se como uma anônima. Diz que não foi educada para ser professora, pois agora percebe que foi educada para reivindicar seus direitos, lutar por ser alguém e ela, como professora formada, sente que não é ninguém, em contradição ao status que usufruía quando lecionava lá na fazenda, tendo estudado, naquela época, somente até a $4^{\mathrm{a}}$ série. A trajetória de vida de Esperança sempre esteve ligada à educação. Desde criança, quando trabalhava na zona rural, conviveu com o sonho de ser professora e esse sonho foi se concretizando aos poucos. Casou-se muito jovem e depois nasceram seus filhos, mas nunca abandonou seus sonhos e mesmo diante de tantos obstáculos conseguiu dar continuidade aos seus estudos. Fez o Ensino Médio em nível de magistério, mas abandonou temporariamente o desejo de ter um curso superior, pois, naquele momento, a família estava em primeiro lugar. Acontecimentos pessoais fizeram sua vida tomar uma nova direção, mas continuou persistente com seus sonhos e, em meio a tantas dificuldades, conseguiu ter um diploma de curso superior. Finalmente, havia concretizado seu sonho, mas o próprio contexto acabou por transformá-lo. A trajetória de vida de Esperança mostra uma pessoa cheia de "sonhos", em que raras vezes se viu "encarnada" em outra figura que não fosse a de professor. Concordamos com Freire (1996, p. 41), quando este concebe o professor como alguém capaz de "[...] assumir-se como ser social e histórico como ser pensante, comunicante, transformador, criador, realizador de sonhos [grifo nosso], capaz de ter raiva porque capaz de amar". Esperança, em seu relato, explicita que:

\begin{abstract}
[...] Eu tive um grande percurso na educação [...] a educação que eu conheci desde menina e não quero aquela educação, porque foi muito tradicional. Eu apanhei para ler o ABC [...] digo da desmoralização é de pouco tempo para cá. Eu trabalhei na escola Al era uma coisa, eu trabalhei no Colégio EB era uma outra coisa. Hoje eu trabalho na $M$ que é decepcionante. Modelo, não sei de que [...] é uma escola que tem uma boa estrutura [...] uma escola linda e tem tudo para ser uma boa escola. [...] precisamos ter pessoas que tenham coragem de se dispor. Eu vou te dizer que não escondo e vou te dizer: a escola é só a capa; descasca que tu verás o miolo. Ninguém trabalha com compromisso (Esperança, entrevista Jul/2004).
\end{abstract}

Lapo e Bueno (2002) apontam que a atividade docente se constitui em um conjunto de ações específicas que são empreendidas pelo professor durante seu percurso profissional. Contudo, essa vida não está desprendida da vida privada, nem da instituição onde se desenvolve e nem de um contexto mais global. A instituição na qual o professor trabalha está inserida em um contexto complexo e está passando por intensas modificações, exercendo influência sobre a 
Educação, desencadeando uma crise que, ainda que venha crescendo já há algum tempo, tem se agravado nos dias atuais. Essa crise provoca um mal-estar docente, cujas "sequelas" "[...] estão à vista de todos: desmotivação pessoal e elevado índice de absenteísmo e de abandono, insatisfação profissional traduzida numa atitude de desinvestimento e de indisposição constante" (NÓVOA, 1991, p. 20).

De maneira geral, pode-se dizer que essa crise é consequência, sobretudo, das modificações que acontecem na sociedade e que acabam deformando o significado da atividade docente. Esta crise também é resultado do processo por meio do qual a profissão docente se desenvolveu e do modo como está organizada. De acordo com Lapo e Bueno (2002), o conjunto desses aspectos acaba interferindo no envolvimento e na auto-realização do professor com o seu próprio trabalho. A transformação social acelerada, cuja central consequência é o desajustamento do indivíduo, quando perde as referências culturais conhecidas, acaba provocando um choque com a realidade e com o futuro.

Dessa forma, o agravamento do mal-estar docente explica essa falta de entusiasmo. O esvaziamento do sentido útil da formação, que transcorre da sobrevalorização do seu valor de troca e convida os professores à formação. $\mathrm{O}$ depoimento de Esperança parece confirmar isso: "[...] Se você tem Magistério, ganha X. Se eu tenho graduação, não é isso, é Y; se eu tenho pós-graduação, você ganha Z. Você não está pelo que você rende, mas pelo grau de escolaridade que você tem". Entretanto, o custo dessa formação é elevado e Esperança acaba rebelando-se pelo absurdo de transformar essa formação em algo contraditório em relação ao exercício do trabalho docente e ao desenvolvimento pessoal e profissional.

Para Canário (2000), o caráter massivo e obrigatório da formação contínua acaba colocando a maioria dos professores numa situação de déficit e de desvalorização das suas qualidades e das suas competências profissionais. Todavia, torna-se um mal relativamente menor quando comparado às casuais modalidades de avaliação que são sentidas pelo professor como algo ameaçador e acaba contribuindo e produzindo um agravamento da sua crise de identidade. Os relatos de Esperança comprovam que "[...] a história recente da formação contínua tem uma lição moral clara: a formação não dá felicidade" [grifo nosso] (CANÁRIO, 2000, p.
75).

[...] Hoje você é multi, você não é professor. Hoje você tem aquela de dizer: vou dar minha aula de Matemática e vou ver Ciências. [...] eu não sou professora de Ciências [...] a Matemática que eu fiz não tinha nada de Ciências [...] Eu hoje dou Ciências: corpo humano e geografia [...] sou professora de Ciências, porque sou obrigada [...] eu fiz Matemática e ninguém entende isso [...] eu não fiz Geografia, eu fiz foi Matemática.[...] na faculdade ninguém ensina isso [...] os cursos que fiz foram para professores, vi Didática, Psicologia, como tratar um aluno e como dar aula. Tenho medo de estar fazendo um desabafo sobre a educação, mas não estou fazendo. Eu só quero mostrar que não tem nada a ver (Esperança, entrevista Jul/2004).

Essa crise identitária da professora Esperança significa uma crise da maneira de ser e estar na profissão. Essa crise acaba interferindo no próprio ofício e provoca dificuldades na interação social, um descontentamento na profissão e, até mesmo, descrença no seu próprio papel social. As causas que originam essas crises são conhecidas. Dentre elas, incluimos: baixos salários, conflitos na instituição de trabalho; insuficiente prestígio social e insegurança.

Tal crise não é alheia à separação entre o eu pessoal e o eu profissional, principalmente em uma profissão carregada de valores morais e ideais (NÓVOA, 1991). Ou seja, é complicado separar uma maneira de ser pessoal, que inclui crenças, valores morais e aspectos do caráter, de tudo aquilo que compõe a maneira de ser professor, suas crenças a respeito da educação, valores pedagógicos e posturas didáticas. Por maior que seja a semelhança das trajetórias profissionais de professores e as suas origens de classe, cada um desenvolve uma forma própria (pessoal) de organizar as aulas, de movimentar-se em sala, de dirigir-se aos alunos, de abordar didaticamente certo tema ou conteúdo e de reagir diante de conflitos.

De certa forma, o que ocorre é a existência de uma imagem predominante projetada pela sociedade, de um modelo ideal do professor, que ocorre pela concepção da classe profissional de forma coletiva. Se, no cenário educacional, ele é visto como um ator protagonista, que desempenha um papel de sujeito predominante para que qualquer transformação significativa no sistema educativo aconteça, por outro lado, a visão deste profissional de forma coletiva resulta em impasses para a sua própria formação. Tal visão não é coerente com as aspirações sociais deste profissional e as diferentes derivações 
dos modelos educativos propostos para a sua formação e desenvolvimento profissional.

Tal concepção é confirmada por Sacristán (1991, p. 63), ao afirmar que a “[...] clarificação das implicações dos professores na prática está ligada à progressiva libertação dos professores como grupo, ao desenvolvimento de sua profissionalidade e a maior qualidade de ensino". O autor discute que a qualidade do ensino está relacionada ao professor, mas não depende exclusivamente dele. A qualidade do ensino está, também, relacionada ao contexto e às condições em que o professor desenvolve as suas atividades docentes. Portanto, essa imagem de profissionalidade ideal vai além, e é configurada por um conjunto de aspectos arrolados com os valores e os currículos das práticas metodológicas ou da própria avaliação.

Esperança, no início da profissão, não tinha feito curso de graduação, mas sentia-se valorizada e respeitada. Ela enfatiza que, outrora, os professores trabalhavam na disciplina com que tinham afinidade e que, hoje, trabalham com o que não aprenderam: "[...] não quero colocar minha revolta com a educação, mas eu acho que seria bem melhor se fosse assim. Eu não era formada, não tinha graduação, não tinha conhecimento nenhum, eu trabalhava com aquilo que eu aprendi e hoje você não trabalha com o que aprendeu e nem vai aprender".

Para Lapo e Bueno (2002), a capacidade dos sujeitos de se desvencilharem de valores e conceitos enraizados e que determinam ações e comportamentos é limitada pelo medo e pela incerteza que o novo traz. Do mesmo modo, torna-se complicado para os professores ensinar algo que não seja aquilo que foi aprendido e do modo como foi aprendido. As mudanças acontecem, sem dúvida, porém em um ritmo muito mais lento do que seria necessário para seguir as transformações que ocorrem fora da escola. A percepção de que as coisas não estão funcionando bem, aliada à ausência de meios e condições para modificar essa situação, induz os professores a um estado de insatisfação com o trabalho docente.

Essa insatisfação foi observada em alguns relatos de Esperança. Em muitos momentos, afirmou que sua formação não lhe deu embasamento pedagógico para enfrentar as mudanças que ocorrem na educação. "[...] o governo fez investimentos na escola, laboratório de computação, tudo feito em gráfico, tudo lindo e maravilhoso. Pergunta quantos professores foram capacitados para aquilo". Isto é, mesmo em um ambiente "farto" de recursos pedagógicos, a maioria dos professores sente dificuldades em utilizá-los, pois não se sentem capacitados para tanto.

\section{CONCLUSÃO}

Por intermédio deste estudo, foi possível perceber que mudanças acontecem com o professor no seu percurso profissional. Contudo, tais mudanças não ocorrem sem conflitos, sem discussão ou reflexão, sem o outro, sem estudo, sem sistematização e sem correr e assumir riscos. No processo de desenvolvimento profissional do professor, os dilemas, as dúvidas e a própria falta de estabilidade chegam a constituir aspectos do desenvolvimento profissional (IMBERNONN, 2002).

As falas de Esperança evidenciam os momentos de crise que vivencia em sua prática cotidiana. Essas "narrativas de crise" estão relacionadas a alguns fatores como baixos salários, conflitos em sua atual instituição de trabalho, escasso prestígio social e insegurança. Os relatos de Esperança revelam que a formação inicial em nada contribuiu para que enfrentasse as "novas" mudanças ocorridas na educação. A sua falta de entusiasmo está associada ao esvaziamento do sentido útil de sua formação, que decorre da sobrevalorização do seu valor de troca. Suas narrativas de crise mostram que, ao recuperar criticamente sua história, coloca para fora de si toda sua "revolta" e abre uma "porta" que possivelmente mostrará um novo caminho a ser tomado. Esperança mostra indícios de que busca novos desafios para o seu desenvolvimento profissional.

Dessa forma, uma narrativa de crise pode edificar o presente como um momento crítico no duplo sentido da palavra, como um momento decisivo e ao mesmo tempo como um momento no qual o sujeito recupera de forma crítica sua própria história, apropria-se criticamente dela para saber onde se encontra e para decidir seu próprio movimento (LARRROSA, 2002). De acordo com Freire (2003),

[...] somente numa perspectiva histórica em que homens e mulheres sejam capazes de assumir-se cada vez mais como objetos da História, vale dizer capazes de reinventar o mundo numa direção ética e estética mais além dos padrões que aí estão é que tem sentido discutir comunicação na nova etapa da continuidade da mudança e da inovação. 
Assim, o sujeito, ao recuperar criticamente sua história, pode repensar o passado, pensar o presente e (re)construir o seu futuro. $\mathrm{O}$ sujeito, ao recuperar a autoconfiança de outrora, pode enfrentar todos os percalços que vivencia cotidianamente e ainda os muitos que estarão por vir. Segundo Freire (2003), pensar a História como possibilidade é, também, reconhecer a educação como possibilidade, reconhecendo que a educação não pode tudo, mas pode alguma coisa e que sua força reside em sua própria fraqueza. Com essa perspectiva, uma das tarefas dos educadores,

[...] é descobrir o que historicamente pode ser feito no sentido de contribuir para a transformação do mundo, de que resulte um mundo mais "redondo", menos arestoso, mais humano, e em que se prepare a materialização da grande Utopia: Unidade em diversidade(FREIRE, 2003, p. 36).

\section{REFERÊNCIAS}

BUENO, B. O.e LAPO, F. R. O abandono do magistério: vínculos rupturas com $\mathrm{o}$ trabalho docente. PSICOL.USP, 2002, vol.13, n. 2, p.243276

CANÁRIO, R. A experiência portuguesa dos centros de formação das associações das escolas. In: MARIN, A. J. (Org). Educação Continuada. Campinas, SP: Papirus, 2000.

CONNELLY, F. M. e CLANDININ, D. J. Relatos de experiência e investigación narrativa. In: LARROSA, J. E. et al. Déjame que te cuente: ensaios sobre narrativa y educación. Barcelona: Editorial Laertes, 1995.

FREIRE, P. Política e educação. São Paulo: Cortez, 2003.(Coleção Questões da Nossa Época; v. 23)

GARNICA, A. V. M. História oral e educação matemática: de um inventário a uma regulação. ZETETIKÉ. Campinas, SP: UNICAMP-FECEPEM, v. 11, n. 19. p. 09-55, 2003.

GONÇALVES, T. O. Formação e desenvolvimento profissional de formadores de professores: o caso dos professores de Matemática da UFPa. Campinas, SP, 2000, 207p. Tese (Doutorado em Educação Matemática) - Centro de Educação, Universidade Estadual de Campinas.
IMBERNÓN, F. Formação docente e profissional: forma-se para a mudança e a incerteza. 3. ed. São Paulo, Cortez, 2002. (Coleção Questões da Nossa Época; v. 77)

.La Formación del Profesorado. Barcelona: Ediciones Paidós, 1994

LARROSA, J. Niestsche \& a Educação. Belo Horizonte: Autêntica, 2002

MELO, G. A. A formação inicial e a iniciação científica: investigar e produzir saberes docentes no ensino de álgebra elementar. Campinas, SP, 2003, 242p. Tese (Doutorado em Educação) - Centro de Educação, Universidade Estadual de Campinas

NÓVOA, A. O passado e o presente dos professores. In: NÓVOA, A. (Org). Profissão professor. Porto: Porto Editora, 1991. 